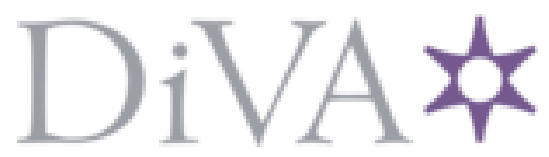

http://www.diva-portal.org

\title{
Postprint
}

This is the accepted version of a paper published in European Neuropsychopharmacology. This paper has been peer-reviewed but does not include the final publisher proof-corrections or journal pagination.

Citation for the original published paper (version of record):

Bahmanyar, S., Sundstrom, A., Kaijser, M., von Knorring, A., Kieler, H. (2013)

Pharmacological treatment and demographic characteristics of pediatric patients with Attention

Deficit Hyperactivity Disorder, Sweden.

European Neuropsychopharmacology, 23(12): 1732-1738

http://dx.doi.org/10.1016/j.euroneuro.2013.07.009

Access to the published version may require subscription.

N.B. When citing this work, cite the original published paper.

Permanent link to this version:

http://urn.kb.se/resolve?urn=urn:nbn:se:uu:diva-2 13907 


\section{Pharmacological treatment and demographic characteristics of pediatric patients with Attention Deficit Hyperactivity Disorder, \\ Sweden}

Authors: Shahram Bahmanyar, $\mathrm{MD} \mathrm{PhD}^{1}$, Anders Sundström, $\mathrm{PhD}^{1}$, Magnus Kaijser, $\mathrm{MD}$ $\mathrm{PhD}^{1}$, Anne-Liis von Knorring MD $\mathrm{PhD}^{2}$ Helle Kieler, $\mathrm{MD} \mathrm{PhD}^{1}$

\section{Affiliations:}

${ }^{1}$ Centre for Pharmacoepidemiology and Clinical Epidemiology Unit, Department of Medicine, Karolinska Institutet, Sweden

${ }^{2}$ Department of Neuroscience, Child and Adolescent Psychiatry, Uppsala University, Uppsala, Sweden

Running title: Pharmacological treatment of pediatric patients with ADHD

Correspondence to:

Shahram Bahmanyar, MD, PhD

Associate professor

Centre for Pharmacoepidemiology

Department of Medicine, Karolinska Institutet

Karolinska Hospital

SE-171 76 Stockholm, Sweden

Phone: $+46(0) 851779323$

Fax: +46 (0)8 51779304

E-mail: Shahram.Bahmanyar@ki.se 


\section{Abstract}

The aim of this study was to describe the pediatric population with ADHD and their pharmacological treatment. Using the Swedish National Patient Register and the Prescribed Drug Register we identified individuals below 19 years of age who were diagnosed or medically treated for ADHD for the first time 2006-2007. The unique patient identifiers were used to link information from the two registers to describe demographic characteristics, hospital care and drug treatments. Logistic regression model estimated the association between age, sex, frequency of hospitalization, diagnosis or treatment for other mental disorders and risk of gap in the treatment. Totally the study included 7,931 patients of whom $74 \%$ were males. The mean age at first diagnosis was 12 years. Some $84 \%$ were medically treated for ADHD and approximately $90 \%$ received methylphenidate as the first substance. Combination therapy was rare and the most common combination was methylphenidate and atomoxetine. More than 55\% of the patients, which could be followed up for two years after start of treatment, had at least one treatment gap of six months. Older age at diagnosis, lower number of hospitalizations and comorbidity with other mental disorders increased risks of gaps in medication. Approximately one fifth of the patients recorded in the National Patient Register as diagnosed with ADHD did not receive pharmacological treatment. Medication adherence seems to be low, when measured as gaps in treatment.

Key words: Attention Deficit Disorder with Hyperactivity; methylphenidate; atomoxetine; amphetamine; dextroamphetamine; pediatrics; cohort study. 


\section{Introduction}

Attention Deficit Hyperactivity Disorder (ADHD), characterized by concentration difficulties, hyperactivity and impulsivity, affects 5 to 10 percent of children and adolescents and approximately $4 \%$ of adults.(Biederman, 2005) In Sweden 3-6\% of children in school age are diagnosed with this disorder and it seems that males have 2-3 fold higher risks.(Socialstyrelsen, 2004)

Patients with a diagnosis of ADHD have increased risks for other psychiatric morbidity and social problems. The children with ADHD are at higher risk of becoming drug abusers later in life. (Yoshimasu et al., 2012) Approximately 80\% of children and adults with ADHD reported to have at least one additional mental disorder, such as oppositional defiant disorder, anxiety disorder and depression. (Kadesjo and Gillberg, 2001; Rodriguez et al., 2007)

Pharmacological treatment of ADHD should be considered when psychological treatments are insufficient alone or if the criteria for Hyperkinetic Disorder according to ICD10 criteria are fulfilled. (Taylor et al., 2004) According to the European recommendation methylphenidate should be the first choice. (Taylor et al., 2004) A recent study (Zoega et al., 2011) showed that a considerable national variation in use of ADHD drugs exists between the Nordic countries. However, the study found that methylphenidate was the most commonly used ADHD drug in all countries. Zetterqvist et al. (Zetterqvist et al., 2012) in a populationbased Swedish study reported an increase in the number of prescriptions dispensed for ADHD drugs from 2006 to 2009 and a high rate of treatment discontinuation among these patients. Recently, Janols et al. (Janols et al., 2009) described the use of central stimulants in ADHD in Sweden using information from the Medical Products Agency's database on named patient use. Information on demographic characteristics, such as age, sex, and concomitant drug treatment was, however, not addressed.

Aims of the study 
The aims of this study were to describe pharmacological treatment and factors influencing medically treatment in pediatric patients diagnosed with ADHD. In particular, we investigated A) association between some important characteristic factors - including age, frequency of hospital contact, diagnosis of other psychiatric disorders, and use of other classes of psychotropic medications - on the one hand and initiation of pharmacological treatment for ADHD and gap in treatment on the other B) type of medication received by the patients, combination therapy and lack time between diagnosis and pharmacological treatment C) proportion of patients in the cohort who are treated with psychotropic drugs other than ADHD drug. 


\section{Experimental Procedures}

All patients who, for the first time, received a diagnosis of ADHD or treatment for ADHD before 19 years of age in Sweden between January $1^{\text {st }} 2006$ and December $31^{\text {st }} 2007$ were identified using the National Patient Register and the Prescribed Drug Register. The patients were followed until December $31^{\text {st }} 2009$. The National Patient Register held by the National Board of Health and Welfare includes data on all individual hospitalizations, since 1987, and information on hospital based outpatient care, since 2001. Each record contains information on sex, age, place of residence, hospital, dates of admission and discharge or visits and diagnoses. The diagnoses were coded according to the International Classification of Diseases (ICD) $10^{\text {th }}$ revision during the study period and the code F90.0 was used to identify patients with a diagnosis of ADHD. In Sweden, patients with ADHD are mainly diagnosed and treated by psychiatrists, pediatric psychiatrists and pediatric neurologists, and the DSM-IV criteria for diagnosis of ADHD are used. In case of an indistinct diagnosis the diagnosis for hyperactivity (ICD-10 code R46.3) might be used.

The Swedish Prescribed Drug Register, established in July 2005 is updated monthly and contains information on dispensed medicines including dates of prescription and dispensing and certain information concerning the prescriber.(Wettermark et al., 2007) We obtained information on purchases of all drugs used for treatment of ADHD (methylphenidate, atomoxetine, amphetamine and dexamphetamine recorded with the ATC-codes N06BA04, N06BA09, N06BA01 and N06BA02, respectively) and other psychotropic medications for the cohort. Both registers include information on the Swedish National Registration Number, an individually unique personal identifier assigned to every Swedish resident from birth or immigration, which enables linkages between the registers.

For deceased individuals we retrieved information on date of death form the National Board of Health and Welfare. 
By including subjects with a first time ADHD diagnosis or treatment after January $1^{\text {st }}$ 2006 we identified 7,931 patients of whom 5,380 were included in the National Patient Register and an additional 2,551 in the Swedish Prescribed Drug Register.

\section{Statistical analyses}

We estimated the incidence of ADHD during the study period and prevalence of pharmacological treatment in the Swedish population below 19 years of age $(n=2,055,847)$. Pharmacological treatment was assessed by substance. We also performed stratified analyses by sex, age (age groups: $<5,5-9,10-14,15-18$ ), ward level (in-patient versus out-patient) and residential place (the six Swedish health-care regions i.e. Uppsala-Örebro, StockholmGotland, South, South-east, West and North).

The prevalence of combination therapies, and gaps in pharmacological treatment were also investigated. Combination therapy was defined as having a dispensing of two or more ADHD drugs during a period of six-month. Gap in treatment was defined as no purchase during a period of six-month followed by a resume of medication. The gaps were counted during a period of two years among children and adolescents who had at least two years follow-up after the start of pharmacological treatment $(n=5,985)$. The cumulative incidence of pharmacological treatment - the probability of receiving pharmacological treatment - after a diagnosis of ADHD was also estimated. Moreover, we investigated if the patients in the cohort had any record of other psychiatric disorders or treatment with other classes of psychotropic medications from July 2005 to the end of the study period.

Logistic regression models were used to investigate the association between demographic factors and risk of initiating ADHD treatment. As demographic factors we included sex, age (age groups: $<5,5-9,10-14,15-18$ ), frequency of hospital contact (number of records: 1, 2-3, >3), history of other psychiatric disorders (yes, no; ICD-10 codes: F00-F99 
or the corresponding codes according to the earlier versions of ICD, and excluding the codes for ADHD) and treatment with other classes of psychotropic medications (yes, no). For those who received pharmacological treatment we studied the association between these factors and risk of having a gap in medication. We used univariate models to estimate the crude relative risks and multivariate analyses to estimate adjusted relative risks.

As the diagnostic accuracy of ADHD could be a concern we reanalyzed the data restricted to those who had at least two recorded episodes with a diagnosis of ADHD in the Patient Register. Moreover, we studied characteristics of the individuals who filled prescriptions for drugs used for treatment of ADHD but with no record in the National Patient Register.

The study was approved by the regional ethics board at Karolinska Institutet. 


\section{Results}

The study included 7,931 individuals who, for the first time, were diagnosed or medically treated for ADHD during 2006-2007, which corresponds to 193 per 100,000 persons per year (95\% CI 189-197). Although there was a fluctuation in the number of patients recorded with ADHD diagnosis by month, a clear increasing trend was evident during the study period. Of the cohort $74 \%$ were male (table 1). During the study period $6,649(84 \%)$ of the cohort received at least one of the substances used for treatment of ADHD. Multivariate analysis showed no significant association between sex and treatment for ADHD. Adolescents 10-14 years old at entry had the highest risks for pharmacological treatment and number of hospital contacts was positively associated with probability of treatment (table 2). Patients treated with other classes of psychotropic medications had higher risks for pharmacological treatment for ADHD compared with those who were not treated with these medications.

Of the 5,380 patients with ADHD in the National Patient Register $81 \%$ had two or more records with the diagnosis and $76 \%$ had received at least one of the substances used for treatment of ADHD. Characteristics of the 2,551 individuals who filled prescriptions for an ADHD drug, but with no record in the National Patient register were similar to those with records in both registers (data not shown).

\section{Pharmacological treatment}

Methylphenidate and atomoxetine were first line of therapy for treating the majority of patients and amphetamine and dexamfetamine were rarely used (Table 3).

Among the 6,649 patients with ADHD and drug treatment 2,708 (40.7\%) received only long-acting methylphenidate during the study period, 1,213 (18.2\%) had both long- and shortacting methylphenidate and $382(5.7 \%)$ had not received methylphenidate during the study period. The remaining 2,346 (35.3\%) patients were treated with methylphenidate and one of the other substances. 
The number of patients who purchased ADHD drugs for the first time varied by season. The lowest dispensing was in July and December. During the study period an increasing number of patients initiated treatment with drugs used for ADHD. Approximately $65 \%$ of those diagnosed with ADHD received at least one medication up to one year after the diagnosis and at the end of follow-up nearly $82 \%$ had ever had pharmacological treatment (Figure 1).

The number of defined daily dose for each prescription was estimated based on the package size and recorded in the Swedish Prescribed Drug Register. Based on the estimated defined daily doses the mean duration of the prescriptions for different substances were between 22 and 76 days.

The ADHD drugs were mainly prescribed by pediatricians (42\%), pediatric psychiatrists (38\%), and psychiatrists (11\%).

\section{Geographical differences}

Rates of ADHD diagnosis differed between the different regions of Sweden (less than 165 new cases per 100,000 inhabitants per year in the southern regions versus 225 cases in the Western regions) and so did drug treatments. The Western regions had the highest rate of dispensed prescriptions with methylphenidate $(4,554 / 100000$ inhabitants compared with $2,664 / 100000$ inhabitants in southeast). Atomoxetine was used most frequently in the Central region (1,235/100 000 inhabitants compared with 699/100 000 inhabitants in southeast).

\section{Combination therapy, gap in treatment and medication adherence}

Of the 6,649 patients with ADHD and drug treatment, $302(4.5 \%)$ had received at least two drugs, and atomoxetine was the most common drug in combination therapy. A total of 4,946 (74.4\%) patients received only one substance, 1,670 (25.1\%) two substances and 33 
$(0.5 \%)$ received three substances or more.

Single use was rare, with $456(6.9 \%)$ having one dispensing only $(6.3 \%$ methylphenidate, and $0.6 \%$ atomoxetine) and $358(6.3 \%)$ with two dispensings. When we restricted the analyses to include only the 5,985 patients who had at least two years of followup after start of pharmacological treatment, 2,609 (43.6\%) patients had one six-month-gap in their treatment, and $241(4.0 \%)$ patients had two or more gaps. There was a higher proportion of females with one or more gaps in treatment when compared to males (53\% versus $46 \%$ ). However, multivariate analysis showed no significant differences between males and females (table 2). Age below five years or several hospital contacts were associated with decreased risks of having a gap in pharmacological treatment. Those with a record of other mental disorders had $30 \%$ increased risk of having gap ( $\mathrm{OR}=1.3,95 \% \mathrm{CI} 1.2-1.5)$. Approximately $40 \%$ of the patients stopped their medication during the last six months of follow-up which could be a gap or discontinuation.

\section{Other psychiatric disorders}

Approximately half of the patients had at least one record with other mental disorders in the National Patient Register, such as a depressive episode, panic disorder, generalized anxiety disorder or pervasive developmental disorders. Females had more often other psychiatric disorders compared with males $(57 \%$ versus $45 \%$, p $<0.01)$.

A third of the patients had at least one other psychotropic medication, such as hypnotics, sedatives or antidepressants (table 4). Females had more often hypnotics and sedatives compared with males ( $43 \%$ versus $29 \%, \mathrm{p}<0.01)$

There was practically no impact on the results when the analyses were restricted to those who had at least two records of an ADHD diagnosis (data not shown in tables). 


\section{Discussion}

This nationwide study showed that a majority of the patients in hospital in- or outpatient care received medications for their disorder up to one year after being diagnosed with ADHD. Two years after the initial diagnosis 20 percent had no medication for ADHD. Methylphenidate was the most common drug, particularly long-acting methylphenidate. Adolescents 10-14 years old at entry had the highest risks for pharmacological treatment and number of hospital contacts was positively associated with probability of treatment. We observed also that patients treated with other classes of psychotropic medications had higher risks for pharmacological treatment for ADHD compared with those who were not treated with these medications. Combination therapy was rare and the most common combination therapy was methylphenidate and atomoxetine. More than half of the patients had one or more treatment gaps of six-months during a two-year period.

Amphetamine and dexamphetamine are rarely used for treating ADHD patients in Sweden. A period of increasing illegal abuse of amphetamine and prescription of central stimulant preparations on unclear indications in Sweden during the 1960s lead to very limited clinical use of central stimulant because of strict regulations by the National Board of Health and Welfare.(The Swedish Medical Products Agency, 1999) Although amphetamine and dexamfetamine are not approved for treatment of ADHD in Sweden they can be used on named patient basis after approval by the regulatory authority. However, considering the low use, it seems that the complex procedure and bureaucracy to get an individual license prohibits the medical doctors to prescribe these medications in Sweden.

The incidence of clinical cases of ADHD among children and adolescent during the study period was 193 per 100,000 persons per year and an increasing trend in the number of patients with a first time diagnosis of ADHD and/or initiating ADHD treatment. The observed increasing pattern is in line with the findings in other industrialized countries such as Norway, 
Iceland, the Netherlands, Germany, and the USA.(Asheim et al., 2007; Donker et al., 2005; Hugtenburg et al., 2004; Olfson et al., 2003; Schmidt-Troschke et al., 2004; Zoega et al., 2007) The result of this study is consistent with the recently reported increased prevalence of pharmacological treatment for ADHD in Sweden and UK. (McCarthy et al., 2009; Zetterqvist et al., 2012) It is conceivable that an awareness of ADHD and the increasing general knowledge concerning this disorder might have improved reporting and coverage over time. (Socialstyrelsen, 2010a) However, a true increase cannot be ruled out as the prevalence of some of the risk factors for ADHD, such as increasing maternal age, body weight and stress, also increased during last decades. (Thapar et al., 2011) In addition, considering the complete coverage in the Prescribed Drug Register the increase in the number of new patients treated with drugs for ADHD possibly reflects an increase in the number of patients also diagnosed with ADHD.

The data showed considerable differences in rate of ADHD and drug treatment in different regions of Sweden, but also within different quite similar countries with similar healthcare resources (Zoega, et al., 2011). The regional differences are consistent with what has been recorded from other countries.(Cohen and Hesselbart, 1993; Gumy et al., 2010) Variation in adaption of new information and awareness of the problems related to ADHD among parents, teachers, and physicians could be the reason for the observed geographical differences in the diagnosis and treatment.(Bussing et al., 2003) The level of availability and distribution of healthcare resources such as specialist clinics and specialists cannot explain the regional differences of diagnosis or prescription.(Socialstyrelsen, 2010b)

The low medication adherence among patients with ADHD is also consistent with the findings in previous studies.(Hodgkins et al., 2011; Marcus and Durkin, 2011; McCarthy et al., 2009; Zetterqvist et al., 2012) This study showed that more than half of the patients had one or more treatment gaps of six-months during a two-year period. The reasons for the poor 
adherence are unknown to us and the data, which can be obtained from the registers does not allow for analysis of how disease severity and psychological development may affect medication adherence. Low risk of gaps among the youngest age group could be explained by a higher support by parents or their possibility to influence their child's medication. It is possible that those with gaps in treatment had less severe ADHD. However, the results in which those with higher number of hospital contact had lower adherence is not consistent with this speculation as the most severe cases are more impulsive and inattentive. Clinical experience also shows that in many cases entrance into adolescence results in refusal to take psychotropic medication. Moreover, those with diagnosis or treatment for other classes of psychotropic medications had poorer adherence. It is also possible that the observed gaps were the periodic medication free periods recommended by their physicians. However, a medication free period should last not more than a few weeks. (van de Loo-Neus et al., 2011) Therefore, a gap of six-months should be considered as low medication adherence. It has been reported that the beneficial effect of stimulant medications appears to stop working two to three years after treatment has been initiated. (Nieweg, 2010; van de Loo-Neus et al., 2011) The high proportion of the patients who stopped their medication after two years in this study is consistent with previous reports. It is worth mentioning that data on the effectiveness of long-term atomoxetine treatment is lacking (van de Loo-Neus et al., 2011) and due to small number of patients who were prescribed only atomoxetine we could not investigate its longterm effectiveness.

The strengths of our study include the large sample size and population based design, but the study also has some limitations. Considering that ADHD is primarily treated in outpatient setting some patients might not be included in our cohort. Therefore, the estimated incidence might be an underestimation of the real incidence. Another caveat is that we did not have information on the indications for treatment, but it should be noted that ADHD is the 
only licensed indication for methylphenidate and atomoxetine use in Sweden. To our best of knowledge there is no established definition for a gap in treatment for patients with ADHD and the defined gap in this study was determined based on treatment routines for ADHD and the characteristics of the data. Treatment practices for patients with ADHD include shorter gaps such as stopping medication during weekends and summer holidays. Moreover, according to the rules in Sweden a dispensing lasts a maximum of three months. Therefore, we applied a conservative approach and defined a gap in treatment as no purchase during a period of six-month.

In conclusion, the number of patients diagnosed and treated for ADHD is increasing, which could be due to an increased awareness about this disorder. Approximately one fifth of patients recorded with an ADHD diagnosis were not medically treated and among those treated gaps in treatment were common. Methylphenidate was the first line therapy choice and combination therapy was rare. 


\section{References}

Asheim, H., Nilsen, K.B., Johansen, K., Furu, K., 2007. [Prescribing of stimulants for ADHD in Nordland County]. Tidsskrift for den Norske laegeforening : tidsskrift for praktisk medicin, ny raekke 127, 23602362.

Biederman, J., 2005. Attention-deficit/hyperactivity disorder: a selective overview. Biol Psychiatry 57, 1215-1220.

Bussing, R., Gary, F.A., Mills, T.L., Garvan, C.W., 2003. Parental explanatory models of ADHD: gender and cultural variations. Social psychiatry and psychiatric epidemiology 38, 563-575.

Cohen, P., Hesselbart, C.S., 1993. Demographic factors in the use of children's mental health services. American journal of public health 83, 49-52.

Donker, G.A., Groenhof, F., van der Veen, W.J., 2005. [Increasing trend in prescription of methylphenidate in general practices in the north-east of The Netherlands, 1998-2003]. Nederlands tijdschrift voor geneeskunde 149, 1742-1747.

Gumy, C., Huissoud, T., Dubois-Arber, F., 2010. Prevalence of methylphenidate prescription among school-aged children in a Swiss population: increase in the number of prescriptions in the Swiss Canton of Vaud, from 2002 to 2005, and changes in patient demographics. J Atten Disord 14, 267272.

Hodgkins, P., Sasane, R., Meijer, W.M., 2011. Pharmacologic treatment of attentiondeficit/hyperactivity disorder in children: incidence, prevalence, and treatment patterns in the Netherlands. Clinical therapeutics 33, 188-203.

Hugtenburg, J.G., Heerdink, E.R., Egberts, A.C., 2004. Increased psychotropic drug consumption by children in the Netherlands during 1995-2001 is caused by increased use of methylphenidate by boys. European journal of clinical pharmacology 60, 377-379.

Janols, L.O., Liliemark, J., Klintberg, K., von Knorring, A.L., 2009. Central stimulants in the treatment of attention-deficit hyperactivity disorder (ADHD) in children and adolescents. A naturalistic study of the prescription in Sweden, 1977-2007. Nordic journal of psychiatry 63, 508-516.

Kadesjo, B., Gillberg, C., 2001. The comorbidity of ADHD in the general population of Swedish schoolage children. Journal of child psychology and psychiatry, and allied disciplines 42, 487-492.

Marcus, S.C., Durkin, M., 2011. Stimulant adherence and academic performance in urban youth with attention-deficit/hyperactivity disorder. Journal of the American Academy of Child and Adolescent Psychiatry 50, 480-489.

McCarthy, S., Asherson, P., Coghill, D., Hollis, C., Murray, M., Potts, L., Sayal, K., de Soysa, R., Taylor, E., Williams, T., Wong, I.C., 2009. Attention-deficit hyperactivity disorder: treatment discontinuation in adolescents and young adults. The British journal of psychiatry : the journal of mental science 194, 273-277.

Nieweg, E.H., 2010. [Does ADHD medication stop working after 2-3 years? On the surprising, but little-known follow-up of the MTA study]. Tijdschrift voor psychiatrie 52, 245-254.

Olfson, M., Gameroff, M.J., Marcus, S.C., Jensen, P.S., 2003. National trends in the treatment of attention deficit hyperactivity disorder. The American journal of psychiatry 160, 1071-1077.

Rodriguez, A., Ginsberg, Y., Fernholm, A., Nyberg, L., 2007. [ADHD difficult to diagnose in adults. ASRS v1.1 Self-Report Scales valuable help--now translated to Swedish]. Lakartidningen 104, 1398-1400.

Schmidt-Troschke, S.O., Ostermann, T., Melcher, D., Schuster, R., Erben, C.M., Matthiessen, P.F., 2004. [The use of methylphenidate in children: analysis of prescription usage based in routine data of the statutory health insurance bodies concerning drug prescriptions]. Gesundheitswesen 66, 387392.

Socialstyrelsen, 2004. Kort om ADHD hos barn och vuxna - En sammanfattning av Socialstyrelsens kunskapsöversikt, Stockholm.

Socialstyrelsen, 2010a. Mot ett system för verksamhetsuppföljning på psykiatriområdet (Towards a system for monitoring activity on the psychiatric field). Socialstyrelsen (The Sweish National Board of Health and Welfare). 
Socialstyrelsen, 2010b. Tillgång på specialistläkare 2008 (Access to specialist doctors 2008). Socialstyrelsen.

Taylor, E., Dopfner, M., Sergeant, J., Asherson, P., Banaschewski, T., Buitelaar, J., Coghill, D., Danckaerts, M., Rothenberger, A., Sonuga-Barke, E., Steinhausen, H.C., Zuddas, A., 2004. European clinical guidelines for hyperkinetic disorder -- first upgrade. European child \& adolescent psychiatry 13 Suppl 1, 17-30.

Thapar, A., Cooper, M., Jefferies, R., Stergiakouli, E., 2011. What causes attention deficit hyperactivity disorder? Archives of disease in childhood.

The Swedish Medical Products Agency, 1999. Centralstimulantiabehandling vid hyperaktivitetssyndrom med uppmärksamhetsstörning (ADHD) hos barn och ungdomar.

van de Loo-Neus, G.H., Rommelse, N., Buitelaar, J.K., 2011. To stop or not to stop? How long should medication treatment of attention-deficit hyperactivity disorder be extended? European neuropsychopharmacology : the journal of the European College of Neuropsychopharmacology 21, 584-599.

Wettermark, B., Hammar, N., Fored, C.M., Leimanis, A., Otterblad Olausson, P., Bergman, U., Persson, I., Sundstrom, A., Westerholm, B., Rosen, M., 2007. The new Swedish Prescribed Drug Register-opportunities for pharmacoepidemiological research and experience from the first six months. Pharmacoepidemiol Drug Saf 16, 726-735.

Yoshimasu, K., Barbaresi, W.J., Colligan, R.C., Voigt, R.G., Killian, J.M., Weaver, A.L., Katusic, S.K., 2012. Childhood ADHD is strongly associated with a broad range of psychiatric disorders during adolescence: a population-based birth cohort study. Journal of child psychology and psychiatry, and allied disciplines 53, 1036-1043.

Zetterqvist, J., Asherson, P., Halldner, L., Langstrom, N., Larsson, H., 2012. Stimulant and nonstimulant attention deficit/hyperactivity disorder drug use: total population study of trends and discontinuation patterns 2006-2009. Acta psychiatrica Scandinavica.

Zoega, H., Baldursson, G., Halldorsson, M., 2007. [Use of methylphenidate among children in Iceland 1989-2006]. Laeknabladid 93, 825-832.

Zoega, H., Furu, K., Halldorsson, M., Thomsen, P.H., Sourander, A., Martikainen, J.E., 2011. Use of ADHD drugs in the Nordic countries: a population-based comparison study. Acta psychiatrica Scandinavica 123, 360-367. 
Table 1. Characteristics of incident pediatric patients with a recorded ADHD diagnosis in the National Patient Register or treatment for ADHD as recorded in the Prescribed Drug Register, 2006-2007

\begin{tabular}{lcc} 
& Number & Percentage \\
\hline Overall & 7931 & 100
\end{tabular}

Sex

Male $\quad 5830 \quad 73.5$

Female $\quad 2101 \quad 26.5$

Age

$\begin{array}{lll}<5 & 126 & 1.6\end{array}$

$\begin{array}{lll}5-9 & 2049 & 25.8\end{array}$

$\begin{array}{lll}10-14 & 3379 & 42.6\end{array}$

$\begin{array}{lll}15-18 & 2377 & 30.0\end{array}$

Mean (SD) $12.0(3.7)$ 
Table 2. Crude and adjusted Relative Risks (RR) and 95\% Confidence Intervals (CI) for the association between some important characteristic factors and initiation of pharmacological treatment for ADHD, gap in treatment

\begin{tabular}{llll}
\hline Subjects Event & $\begin{array}{l}\text { Crude RR (95\% } \\
\text { CI) }\end{array}$ & $\begin{array}{l}\text { Adjusted RR } \\
(95 \% \mathrm{CI})\end{array}$
\end{tabular}

\begin{tabular}{ccccc}
\hline $\begin{array}{c}\text { Treatment }^{\mathrm{b}} \\
\text { Sex }\end{array}$ & 5380 & 4098 & & \\
Male & 3944 & 3010 & $1.0(0.9-1.2)$ & $1.0(0.8-1.2)$ \\
Female & 1436 & 1088 & Reference & Reference \\
Age, year & & & & \\
$<5$ & 109 & 41 & $0.2(0.1-0.3)$ & $0.2(0.1-0.4)$ \\
$5-9$ & 1537 & 1195 & $1.0(0.9-1.2)$ & $1.1(0.9-1.4)$ \\
$10-14$ & 2257 & 1796 & $1.3(1.1-1.5)$ & $1.4(1.2-1.7)$ \\
$>14$ & 1477 & 1066 & Reference & Reference
\end{tabular}

Frequency of hospital contact

$\begin{array}{lllll}1 & 1072 & 381 & \text { Reference } & \text { Reference } \\ 2-3 & 1347 & 925 & 4.0(3.4-4.7) & 4.0(3.4-4.8) \\ >3 & 2961 & 2792 & 30.0(24.5 .36 .6) & 29.4(24.3 .36 .0)\end{array}$

Other psychiatric disorders
No
Yes
Other classes of

2411

1804

Reference

Reference

2969

2294

$0.8(0.7-0.9)$

$0.9(0.8-1.1)$ psychotropic medications

\begin{tabular}{ccccc} 
No & 3655 & 2701 & Reference & Reference \\
Yes & 1725 & 1394 & $1.5(1.3-1.7)$ & $1.3(1.1-1.5)$ \\
\hline $\begin{array}{c}\text { Gap in treatment } \\
\text { Sex }\end{array}$ & 5985 & 2850 & & \\
Male & & & & \\
Mal & 4413 & 2012 & $0.7(0.65-0.8)$ & $0.9(0.8-1.1)$
\end{tabular}


$\begin{array}{lllll}\text { Female } & 1572 & 838 & \text { Reference } & \text { Reference }\end{array}$

Age, year

$\begin{array}{lllll}<5 & 36 & 17 & 0.41(0.21-0.80) & 0.42(0.21-0.82) \\ 5-9 & 1479 & 393 & 0.17(0.14-0.19) & 0.19(0.16-0.22) \\ 10-14 & 2638 & 1187 & 0.38(0.33-0.43) & 0.40(0.35-0.45) \\ >14 & 1832 & 1253 & \text { Reference } & \text { Reference }\end{array}$

Frequency of hospital contact

$\begin{array}{lllll}0 & 2551 & 1435 & 0.9(0.7-1.1) & 0.9(0.7-1.1) \\ 1 & 318 & 190 & \text { Reference } & \text { Reference } \\ 2-3 & 743 & 401 & 0.8(0.6-1.0) & 0.8(0.6-1.1) \\ >3 & 2373 & 824 & 0.4(0.3-0.5) & 0.4(0.3-0.5)\end{array}$

Other psychiatric disorders

$\begin{array}{lllll}\text { No } & 3191 & 1445 & \text { Reference } & \text { Reference } \\ \text { Yes } & 2794 & 1405 & 1.2(1.1-1.4) & 1.3(1.2-1.5)\end{array}$

Other classes of psychotropic medications

$\begin{array}{lllll}\text { No } & 3935 & 1792 & \text { Reference } & \text { Reference } \\ \text { Yes } & 2050 & 1058 & 1.3(1.1-1.4) & 1.1(0.95-1.2)\end{array}$

\footnotetext{
${ }^{a}$ Adjusted for all the variables in the table.

${ }^{\mathrm{b}}$ Initiation of pharmacological treatment for those who had a record in the National Patient Register

${ }^{c}$ Among those who had at least two years follow-up after start of pharmacological treatment for ADHD
} 
Table 3. Type of medication received by the cohort during 2006 to 2009, stratified by sex

\begin{tabular}{|c|c|c|}
\hline & $\begin{array}{l}\text { The first recorded } \\
\text { treatment for each } \\
\text { subject }\end{array}$ & $\begin{array}{l}\text { All recorded } \\
\text { purchases } \\
\text { during the study } \\
\text { period }\end{array}$ \\
\hline All cohort & 7931 & - \\
\hline $\begin{array}{l}\text { No pharmacological } \\
\text { treatment }\end{array}$ & 1282 & - \\
\hline Medically treated & $6649(100)$ & $95873(100)$ \\
\hline Male $(\%)$ & $4896(73.6)$ & $72021(75.1)$ \\
\hline Female $(\%)$ & $1753(26.4)$ & $23852(24.9)$ \\
\hline Methylphenidate & $5915(89.0)$ & $74730(78.0)$ \\
\hline Male (\%) & $4357(73.7)$ & $55793(74.7)$ \\
\hline Female (\%) & $1558(23.4)$ & $18937(25.3)$ \\
\hline Atomoxetine & $725(11.0)$ & $20560(21.5)$ \\
\hline Male (\%) & $533(73.5)$ & $15814(76.9)$ \\
\hline Female $(\%)$ & $192(26.5)$ & $4746(23.1)$ \\
\hline Amphetamine & $5(0.1)$ & $358(0.4)$ \\
\hline Male (\%) & $3(60.0)$ & $249(69.6)$ \\
\hline Female $(\%)$ & $2(40.0)$ & $109(30.5)$ \\
\hline
\end{tabular}


Dexamphetamine $\quad 4(0.1) \quad 225(0.2)$
Male (\%)
$3(75.0)$
$165(73.3)$

Female (\%)

$1(25.0)$

60 (26.7) 
Table 4. Number of patients in the cohort who are treated with different psychotropic drugs, ATC-codes: N06BA04, N06BA09, N06BA01 and N06BA02 are excluded ${ }^{\mathrm{a}}$

\begin{tabular}{|c|c|c|}
\hline & $\begin{array}{l}\text { Number } \\
\text { of } \\
\text { patients }\end{array}$ & $\%$ \\
\hline Anesthetics (N01) & 69 & 0.9 \\
\hline Analgesics (N02) & 395 & 5.0 \\
\hline Antiepileptics (N03) & 447 & 5.6 \\
\hline Anti-parkinson drugs (N04) & 12 & 0.2 \\
\hline Psycholeptics (N05) & 1648 & 20.8 \\
\hline Antipsychotics (N05A) & 421 & 5.3 \\
\hline Anxiolytics (N05B) & 301 & 3.8 \\
\hline Hypnotics and sedatives (N05C) & 926 & 11.7 \\
\hline Psychoanaleptics (N06) & 938 & 11.8 \\
\hline Antidepressants (N06A) & 928 & 11.7 \\
\hline Psychostimulants, agents used for & 10 & 0.1 \\
\hline ADHD and nootropics (N06B) & & \\
\hline Other nervous system drugs (N07) & 30 & 0.4 \\
\hline
\end{tabular}


Figure 1. Proportion of the patients with ADHD diagnosis $(\mathrm{n}=5,380)$ who received pharmacological treatment during two years follow-upa, 2006-2009. 